\section{Management of myocardial stunning associated with electroconvulsive therapy guided by hyperventilation echocardiography}

Daniel T. Eitzman, MD, David S. Bach, MD, and Melvyn Rubentire, MU Ann Arbor, Mich.

Cardiovascular complications associated with electroconvulsive therapy (ECT) for depression include dysrythmias, myocardial infarction, cardiac arrest, exaggerated hypertensive responses, and transient myocardial dysfunction. ${ }^{1-3}$ A variety of ECG changes have been demonstrated to occur in association with ECT and other central nervous system events. Although some studies have suggested that these ECG abnormalities are not typically associated with

From the Cardiology Division, University of Michigan Hospital. Reprint requests: Daniel Eitzman, MD, Division of Cardiology, $1500 \mathrm{E}$ Medical Center Dr., Ann Arbor, MI 48109-0022.

AM HEART J 1994;127:928-9.

Copyright 1994 by Mosby-Year Book, Inc.

$0002-8703 / 94 / \$ 3.00+0 \quad \mathbf{4 / 4} / 52094$ heart disease, others have documented transient myocardial dysfunction. ${ }^{3}$ We describe the usefulness of hyperventilation echocardiography in the treatment of a patient with myocardial stunning presumed to be due to coronary vasospasm after $\mathrm{ECT}$.

A 76-year-old woman with severe depression and no history of heart disease was admitted for ECT after medical treatment failed. Initial ECG demonstrated a left anterior fasicular block and septal Q waves caused by septal infarct or possibly the left anterior fasicular block (Fig. 1). Anesthesia was induced with methohexital sodium and succinylcholine. ECT with $15.8 \mathrm{~J}$ induced a generalized tonicclonic seizure that lasted for 30 seconds. Peak blood pressure was $200 / 110 \mathrm{~mm} \mathrm{Hg}$ with a heart rate of 150 heat.s/min. Transient widening of the QRS complex was noted in lead II, the ECG monitoring lead, before the tachycardia and hypertension developed. Fifteen minutes after ECT, the ECG showed $1 \mathrm{~mm}$ of ST-segment elevation in leads $V_{2}$ to $\mathrm{V}_{5}$ and $\mathrm{Q}$ waves in leads II, III, aVF, $\mathrm{V}_{2}$, and $\mathrm{V}_{3}$. Although sedated, the patient denied chest pain or dyspnea. An echocardiogram obtained approximately 30 minutes after ECT revealed distal septal and apical akinesis with myocardium of full thickness. Nitroglycerin was administered intravenously, with complete resolution of the ST-segment

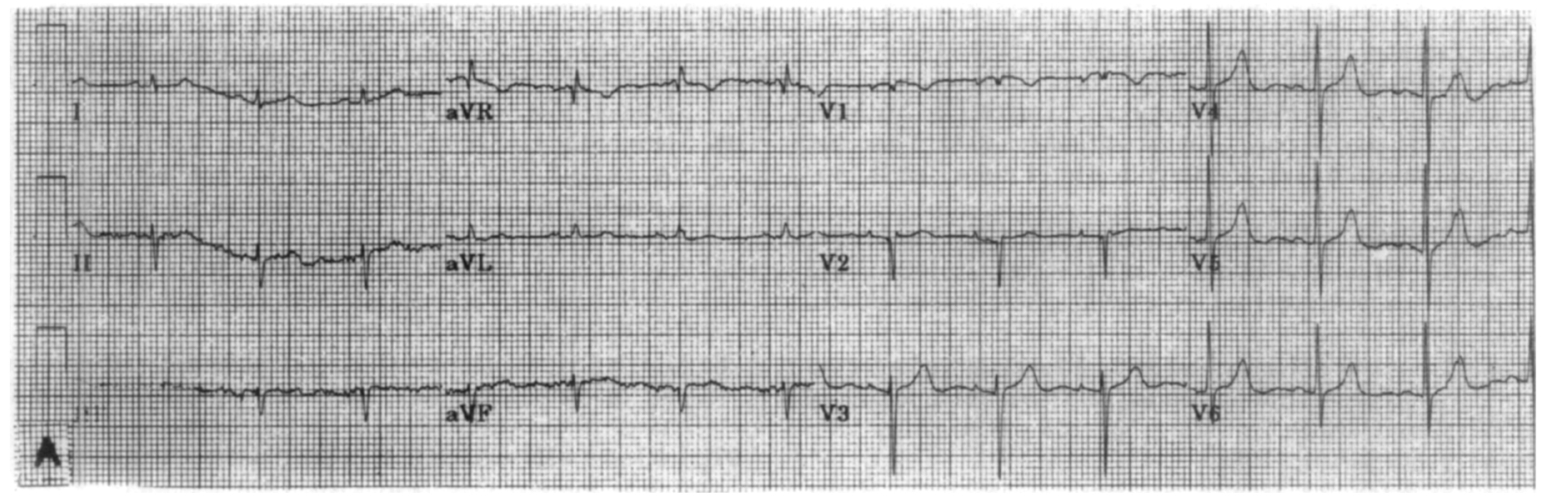

15 MIN AFTER ECT

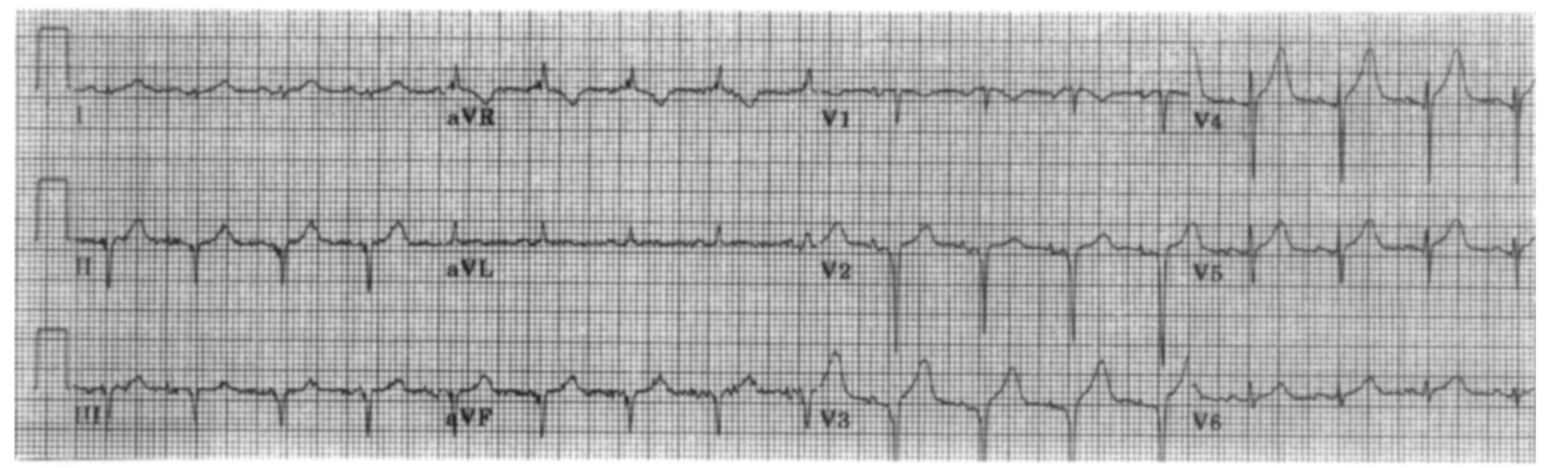

Fig. 1. Flectrocardiograms before (A) and 15 minutes after (B) ECT. 


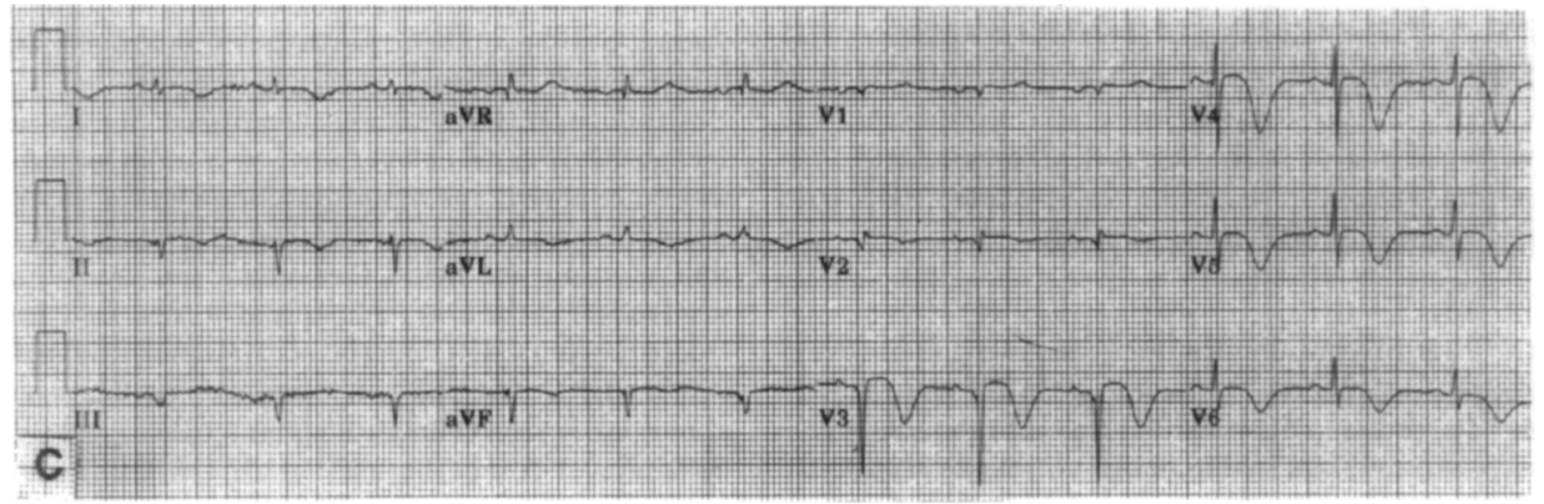

4 DAYS AFTER ECT

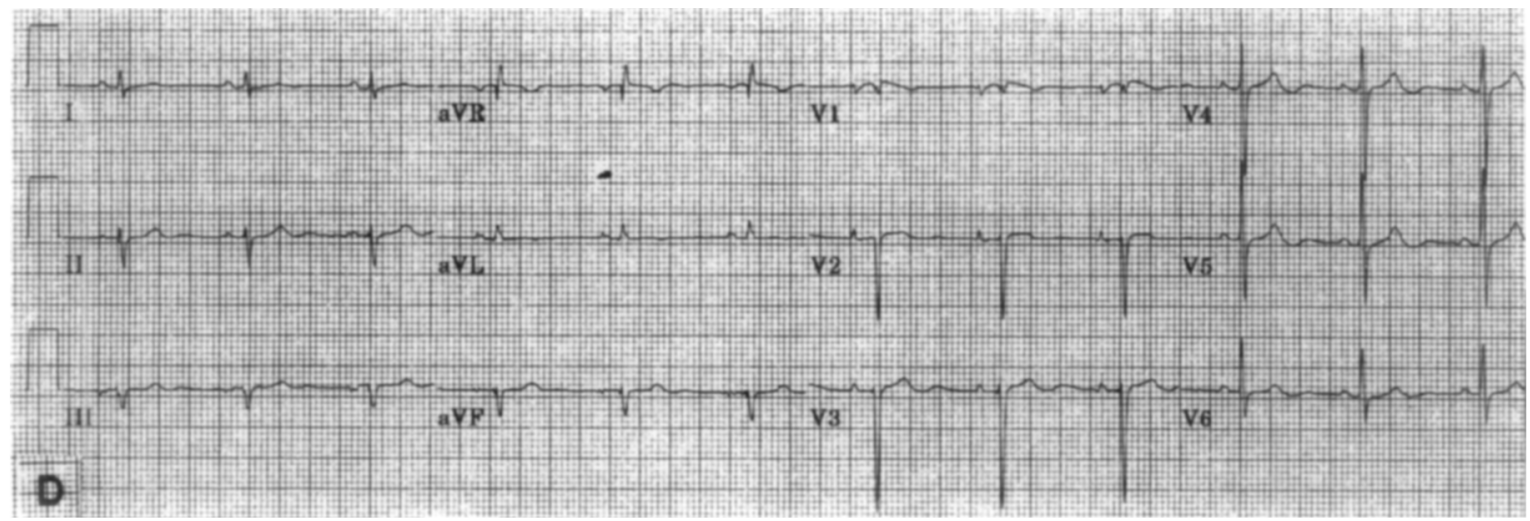

Fig. 1. (cont'd). Electrocardiograms 32 hours after (C) and 4 days after (D) ECT.

elevation by 45 minutes after ECT. The next evening the ECG revealed small $Q$ waves in leads $I I I$, aVF, $V_{2}$, and $V_{3}$ with deep symmetrical $\mathrm{T}$-wave inversions in the anterolateral leads. Creatine kinase levels peaked at $243 \mathrm{IU} / \mathrm{L}$ with $4.9 \% \mathrm{MB}$ fraction. An adenosine thallium nuclear imaging study was performed 3 days later and demonstrated no evidence of resting or adenosine-induced perfusion defects. Coronary artery spasm or plaque rupture were considered likely causes of the transient injury and apparent myocardial stunning. The psychiatrist believed that repeat ECT was essential and requested an opinion regarding when this would be feasible and how a recurrence could be prevented. The patient refused a cardiac catheterization and administration of ergonovine but accepted a hyperventilation echocardiogram to identify possible coronary vasospasm. The baseline echocardiogram performed 6 days after the ECT demonstrated complete recovery of hypokinesis with no wall-motion abnormalities. During the recovery phase after 4 minutes of hyperventilation, akinesis of the septum occurred, which resolved in 15 minutes, a pattern consistent with coronary vasospasm. The patient was started on a regimen of $90 \mathrm{mg} /$ day of long-acting nifedipine. A repeat hyperventilation echocardiogram, performed 2 days later, demonstrated no wall-motion abnormalities. The patient subsequently underwent uneventful ECT without ECG changes.

The utility of hyperventilation echocardiography has been evaluated in the diagnosis and treatment of patients with Prinzmetals' angina and has demonstrated a sensitivity similar to that of ergonovine in patients with active disease $(95 \%$ vs $100 \%)$. The sensitivity is lower in patients with only rare attacks $(55 \%$ vs $77 \%){ }^{4}$ The mechanism of hyperventilation-induced coronary artery spasm is unknown; however, in selected cases it may have excellent clinical utility.

\section{REFERENCES}

1. Dec WG, Stern TA, Welch C. The effects of electroconvulsive therapy on serial electrocardiograms and serial cardiac enzyme values. JAMA 1985;253:2525-9.

2. Gould L, Gopalaswamy C, Chandy F, Kim B. Electroconvulsive therapy-induced ECG changes simulating a myocardial infarction. Arch Intern Med 1983;143:1786-7.

3. Zhu W, Olson DE, Karon BL, Tajik AJ. Myocardial stunning after electroconvulsive therapy. Ann Intern Med 1992; 117:914-5.

4. Previtali M, Ardissino D, Barberis P, Panciroli C, Chimienti M, Salerno JA. Hyperventilation and ergonovine tests in Prinzmetal's angina pectoris in men. Am J Cardiol 1989;63:1720. 